\title{
Susceptibility to PTSD-Like Behavior Is Mediated by Corticotropin-Releasing Factor Receptor Type 2 Levels in the Bed Nucleus of the Stria Terminalis
}

\author{
Maya Lebow, ${ }^{1}$ Adi Neufeld-Cohen, ${ }^{1 *}$ Yael Kuperman, ${ }^{1,2 *}$ Michael Tsoory, ${ }^{1,2}$ Shosh Gil, ${ }^{1}$ and Alon Chen ${ }^{1}$ \\ Departments of ${ }^{1}$ Neurobiology and ${ }^{2}$ Veterinary Resources, Weizmann Institute of Science, Rehovot 76100 , Israel
}

Posttraumatic stress disorder (PTSD) is a debilitating disease, which affects $8-10 \%$ of the population exposed to traumatic events. The factors that make certain individuals susceptible to PTSD and others resilient are currently unknown. Corticotropin-releasing factor receptor type 2 (CRFR2) has been implicated in mediating stress coping mechanisms. Here, we use a physiological PTSD-like animal model and an in-depth battery of tests that reflect the symptomology of PTSD to separate mice into subpopulations of "PTSD-like" and "Resilient" phenotypes. PTSD-like mice are hypervigilant, hyperalert, insomniac, have impaired attention and risk assessment, as well as accompanying attenuated corticosterone levels. Intriguingly, PTSD-like mice show long-term robust upregulation of BNST-CRFR2 mRNA levels, and BNST-CRFR2-specific lentiviral knockdown reduces susceptibility to PTSD-like behavior. Additionally, using a BNST mRNA expression array, PTSD-like mice exhibit a general transcriptional attenuation profile, which was associated with upregulation of the BNST-deacetylation enzyme, HDAC5. We suggest PTSD to be a disease of maladaptive coping.

\section{Introduction}

Posttraumatic stress disorder (PTSD) is a debilitating disorder, in which $8-10 \%$ of those who experienced or witnessed a traumatic event that caused feelings of helplessness or horror (DSM IV) (American Psychiatric Association, 1994) have frequent reexperiencing of the event via flashbacks or nightmares. Physiologically, PTSD patients experience hyperarousal, hypervigilance, and exaggerated startle responses and insomnia. Patients with severe PTSD also show hypothalamic-pituitary-adrenal (HPA) alterations such as elevated corticotropin-releasing factor (CRF) levels (Bremner et al., 1997; de Kloet et al., 2008), blunted adrenocorticotropic hormone (ACTH) response (Ströhle et al., 2008; Yehuda et al., 2004), and hypocortisolemia (for review, see Yehuda, 2009).

CRF receptor type 2 (CRFR2), along with its-specific ligands, urocortin-2 (Ucn2) and urocortin-3 (Ucn3), are hypothesized to be involved in dampening the stress response (Bale and Vale, 2004; Vaughan et al., 1995; Bale et al., 2000; Coste et al., 2000; Kishimoto et al., 2000; Neufeld-Cohen et al., 2010). Initiation of

\footnotetext{
Received Aug. 4, 2011; revised March 4, 2012; accepted March 8, 2012.

Author contributions: M.L., M.T., and A.C. designed research; M.L., A.N.-C., Y.K., S.G., and A.C. performed research; M.L., A.N.-C., Y.K., M.T., S.G., and A.C. analyzed data; M.L. and A.C. wrote the paper.

This work is supported by an FP7 Grant from the European Research Council (\#260463), by research grants from the Israel Science Foundation, Roberto and Renata Ruhman, the Institute for the Study of Affective Neuroscience, and from the Legacy Heritage Biomedical Science Partnership, by a grant from Mr. and Mrs. Mike Kahn, and by research grants from Mr. Jorge David Ashkenazi, Mr. and Mrs. Barry Wolfe, and Nella and Leon Benoziyo Center for Neurosciences. We thank Mr. S. Ovadia for his devoted assistance with animal care. AC is incumbent of the Philip Harris and Gerald Ronson Career Development Chair.

${ }^{*}$ A.N.-C. and Y.K. contributed equally to this work.

Correspondence should be addressed to Dr. Alon Chen, Department of Neurobiology, Weizmann Institute of Science, Rehovot 76100, Israel. E-mail: alon.chen@weizmann.ac.il.

DOI:10.1523/JNEUROSCI.4012-11.2012

Copyright $\odot 2012$ the authors $\quad 0270-6474 / 12 / 326906-11 \$ 15.00 / 0$
}

the stress response is mediated by CRF and its high affinity binding to CRF receptor type 1 (CRFR1) (Heinrichs et al., 1995; Koob and Heinrichs; 1999). While CRFR1 is distributed widely in the brain, CRFR2 is concentrated in-specific stress-related brain areas such as the bed nucleus of the stria terminalis (BNST), dorsal raphe, medial amygdala, and lateral septum (Chalmers et al., 1995; Van Pett et al., 2000).

The BNST is thought to be involved in longer duration fear responses or anxiety in which a sustained apprehensive state persists after the threat has been removed and adaptive response to the threat has subsided (Lee and Davis, 1997; Walker and Davis, 1997) (for review, see Davis et al., 2010). The BNST itself receives glutamatergic innervations from the hippocampus, CRF from the central amygdala, and has substantial innervation to the hypothalamic medial parvocellular neurons, in which CRF is released to initiate the HPA axis (Forray and Gysling, 2004; Dong et al., 2001; Gu et al., 2003; Dong and Swanson, 2004, 2006).

The BNST expresses high levels of CRFR2 in its posterior medial subnuclei, while its anterior includes subnuclei in which CRFR1 is expressed (Chalmers et al., 1995; Van Pett et al., 2000). Lesion studies (Choi et al., 2008a,b) demonstrate that the anteroventral areas activate the HPA axis in response to acute challenge, and the posterior subregions are necessary to inhibit the effects of acute stress. These innervations place the posterior medial BNST as a center for integration of a stress response.

In this study, using a model of PTSD-like behavior, stressenhanced fear learning (SEFL) adapted from Rau et al. (2005), we sought to determine the contribution of CRF family of receptors and ligands to PTSD-like behavior. The persistent stress of the traumatic event is hypothesized to be caused by one of the following possibilities: (1) there is an exaggerated initiation of the stress response via CRF/CRFR1 circuitry, or (2) the restoration to 
homeostasis via the Urocortins/CRFR2 is impaired. In this study, we demonstrated that a long-term imbalance of CRFR2 levels in the BNST causes the behavioral and physiological markers manifested in PTSD-like behavior. Here, we show that mice that phenotypically are hypervigilant and hyperalert, show attention deficits and impaired risk assessment, exhibit insomnia, and additionally have attenuated corticosterone responses, also have dramatically upregulated CRFR2 mRNA levels in the BNST. Interestingly, BNST-specific CRFR2 knockdown (KD) in adult mice reduces the frequency of these phenotypes, which were also found to be associated with modified BNST-expression profile of several key-related genes.

\section{Materials and Methods}

Animal care. Mice were maintained in a pathogen-free temperaturecontrolled $\left(22 \pm 1^{\circ} \mathrm{C}\right)$ mouse facility on a reverse $12 \mathrm{~h}$ light/dark cycle at the Weizmann Institute of Science, according to institutional guidelines. Food and water were given ad libitum. All experimental protocols were approved by the Institutional Animal Care and Use Committee of The Weizmann Institute of Science.

PTSD protocol. Based on the model for PTSD in rats, established by Rau et al. (2005) and Rau and Fanselow (2009), we generated a model for PTSD-like behavior in mice. Our model begins on day 1 , in context A, in which mice receive 14 shocks of $1 \mathrm{~mA}, 1 \mathrm{~s}$ in duration with continuous pulse over $85 \mathrm{~min}$ in variable intervals, representing the "trauma." On day 2 , the same mice receive 5 pulsed shocks of $0.7 \mathrm{~mA}, 1 \mathrm{~s}$ in duration over $5 \mathrm{~min}$ in fixed intervals representing a "trigger" in context B.

Shocks were given in a fear-conditioning apparatus (TSE Systems). Context A consisted of a transparent, Plexiglas cage $(21 \times 20 \times 36 \mathrm{~cm})$ with a metal grid floor and 10 lux illumination. Habituation took place in a room adjacent to the experiment room with red light and white background noise. Animals were transferred to the experiment room in darkness and experiment room lights were kept off. Between animals, the grid and cage were cleaned with $1 \%$ acetic acid solution. Shocks in Context A were comprised of a continuous current pulse. Context B consisted of a black, opaque cage $(21 \times 20 \times 36 \mathrm{~cm})$ with a metal grid floor and black plastic tray under the metal grid. Mice in the experimental cage were subject to $70 \mathrm{~dB}$ background noise and had no illumination. Habituation took place in a room slightly further away from the experiment room than habituation of context A. Shocks in Context B were comprised of a pulsating current with $20 \mathrm{~Hz}$ frequency. Mice were transferred to brightly lit experiment room in small carton cages. Between animals, cages and the metal grid were cleaned with $10 \%$ ethanol solution. Mice were then tested in five behavioral tests: percentage risk assessment, latency to peak startle amplitude, pre-pulse inhibition, marble burying, and total light activity.

Light/dark transfer test. The apparatus for the light/dark transfer test (TSE Systems) consists of a Plexiglas box divided by a partition into two areas; one dark $(14 \times 27 \times 26 \mathrm{~cm})$ the second brightly illuminated $(30 \times$ $27 \times 26 \mathrm{~cm}, 700 \mathrm{lux})$. These areas are connected by a sliding door located at the floor level in the center of the partition. Mice were placed in the dark area and the connecting door was opened to initiate a 5 min test session. The animal's movements were recorded and scored using a camera and automated software (Videomot2, TSE Systems). Time spent in the light arena, number of visits to the light arena, and total distance traveled in the light arena were measured.

Risk assessment. An additional arena of $3 \mathrm{~cm}$ lengthwise by $6 \mathrm{~cm}$ widthwise was programmed into the software tracking measurements surrounding the opening of the lit arena of the light/dark transfer test. Time spent in the risk assessment area and number of visits to the risk assessment area was measured. Percentage risk assessment time was calculated as the amount of time spent in the risk assessment arena as a percentage of total time spent in the lit arena outside of the risk assessment zone.

Startle and prepulse inhibition. Startle response (TSE Systems) protocol was adapted from Neufeld-Cohen et al. (2010). Briefly, mice were placed in a small Plexiglas and wire mesh cage on top of a vibration-sensitive platform in a sound-attenuated, ventilated chamber. A high-precision sensor, integrated into the measuring platform, detected movement.
Two high-frequency loudspeakers inside the chamber produced all the audio stimuli. The acoustic startle response (ASR) session began with 5 min acclimation to white background noise $[65 \mathrm{db}(\mathrm{A})]$ maintained through the whole session. Thirty-two startle stimuli [120db(A), $40 \mathrm{~ms}$ in duration with a randomly varying ITI of $12-30 \mathrm{~ms}$ ] were presented interspersed with an additional 40 startle stimuli randomly preceded by prepulses of either $74 \mathrm{db}(\mathrm{A})(40 \mathrm{~ms}), 78 \mathrm{db}(\mathrm{A})(40 \mathrm{~ms})$, and $82 \mathrm{~dB}(\mathrm{~A})(40$ $\mathrm{ms})$. Latency to peak startle amplitude was also measured both in response to startle stimuli and in response to startle stimuli preceded by prepulses.

Homecage locomotion. Homecage locomotion was assessed using the InfraMot system (TSE Systems). Mice were housed individually for $72 \mathrm{~h}$, in which the first $24 \mathrm{~h}$ were considered habituation to the individual housing conditions. Measurements of general locomotion consisted of two light and two dark cycles in the last $48 \mathrm{~h}$ collected at $10 \mathrm{~min}$ intervals.

Marble burying. Mice were placed in a compartment illuminated by 10 lux with dimensions $(30 \times 27 \times 26 \mathrm{~cm})$ containing $5 \mathrm{~cm}$ autoclaved bedding with 20 marbles centrally arranged 4 by 5 . Mice were then filmed for $30 \mathrm{~min}$. Videos were scored by counting the number of unburied marbles after $25 \mathrm{~min}$, as previously described in Sztainberg et al. (2011).

Application of inclusion criterion for PTSD-like versus resilient mice. Mice that underwent five behavioral tests: percentage risk assessment, reaction time to peak startle response, prepulse inhibition, marble burying, and total light activity, were subcategorized as PTSD-like or Resilient mice based on their behavioral results. For total light activity, for example, the results were sorted from highest to lowest. Of all mice that underwent the five tests (68 mice), 20\% (13 mice) with the highest light activity were given 1 point. The same sorting was done for marble burying, in which results were sorted from highest to lowest and the top $20 \%$ were assigned 1 point. In the case of latency to peak startle amplitude, percentage prepulse inhibition and percentage risk assessment, results were sorted from lowest to highest, as the extreme behavior is reflected in less percentage risk assessment and shorter latency to peak startle amplitude and less percentage prepulse inhibition (ppi). In each of these three tests, 20\% (14 mice) who had the lowest results were given 3 points for percentage risk assessment, 3 points for shortest latency to peak startle amplitude, and 2 points for percentage ppi. Points for each test were determined by factor analysis in which tests were clustered in three separate groups: (1) latency to peak startle amplitude and percentage risk assessment, (2) percentage ppi, and (3) marble burying and total light activity.

The points per animal were tallied. Mice that had totals of 5 or more points were termed PTSD-like. Only mice that had zero points were termed Resilient. The threshold of 5 was set to obtain between as close to $20 \%$ of PTSD-like mice in the population. Overall, $20 \%$ of mice were judged to be PTSD-like and $20 \%$ to be Resilient.

Brain tissue collection. Immediately after decapitation, the brain was removed and placed in a steel brain matrix, $1.0 \mathrm{~mm}$, coronal (model: 51386: Stoelting). The brains were sliced into $2 \mathrm{~mm}$ slices using standard razor blades and were quickly frozen on dry ice. The area of interest was punched out using a microdissecting needle of 13-14 G depending on brain area. Punches were immediately stored at $-80^{\circ} \mathrm{C}$.

RNA extraction and real-time PCR. RNA extraction was performed using 5 PRIME PerfectPure RNA Cell and Tissue kit (5 Prime GmbH). RNA preparations were reverse transcribed to generate cDNA using High Capacity cDNA Reverse Transcription Kit (Applied Biosystems). The cDNA products were used as templates for real-time PCR analysis. Sense and antisense primers were selected to be located on different exons to avoid false-positive results caused by genomic DNA contamination. The following-specific primers were designed using Primer Express software (Applied Biosystems, PerkinElmer): CRFR2: TACCGAATCGCCCTCATTGT, CCACGCGATG TTTCTCAGAAT; CRFR1: TGCCAGGAGATTCTCAACGAA, AAAGCC GAGATGAGGTTCCAG; CRF: GCAGTTAGCTCAGCAAGCTCAC, CA AATGATATCGGAGCTGCG; GR: TGCTGTTTATCTCCACTGAATTAC A, TCCTTAGGAACTGAGGAGAGAAGC; AVP: CGCTCTCCGCTTGTT TCCT,CACTGTCTCAGCTCCATGTCAGA;HDAC5:TGTCACCGCCAG ATGTTTTG,TGAGCAGAGCCGAGACACAG;HDAC2: GGGACAGGCT TGGTTGTTTC, GAGCATCAGCAATGGCAAGT; DNMT1: CCTAGTTC CGTGGCTACGAGGAGAA, TCTCTCTCCTCTGCAGCCGACTCA; DN 
MT3a: CTCGACACAAAAGCACCTGC,AGTATGACGACGATGGGTAC CAG; DNMT3b: TTCAGTGACCAGTCCTCAGACACGAA, TCAGAAGG CTGGAGACCTCCCTCTT; HPRT1: GCAGTACAGCCCCAAAATGG, GGTCCTTTTCACCAGCAAGCT.

Real-time PCRs were performed on a 7500 Real-Time PCR system using fluorescent SYBR Green technology (Applied Biosystems). Reaction protocols had the following format: $10 \mathrm{~min}$ at $95^{\circ} \mathrm{C}$ for enzyme activation followed by 40 cycles of $15 \mathrm{~s}$ at $94^{\circ} \mathrm{C}$ and $60 \mathrm{~s}$ at $60^{\circ} \mathrm{C}$. Melting curve analysis checked the specificity of the amplification products. All reactions contained the same amount of cDNA, $10 \mu \mathrm{l}$ of master mix, and $250 \mathrm{~nm}$ primers to a final volume of $20 \mu \mathrm{l}$.

Corticosterone collection and measurement. Plasma was extracted from blood samples that were collected by tail bleed under basal conditions and 25,75 , and $120 \mathrm{~min}$ following stress initiation. After basal measurements $(0 \mathrm{~min})$, mice were placed in restrainers for $25 \mathrm{~min}$. Peak corticosterone measurements were then taken upon removal from the restrainer. Two different points of recovery were taken at $75 \mathrm{~min}$ and 120 min counting from the basal measurement. All blood samples were collected at 13:00 P.M., $8 \mathrm{~h}$ after beginning of dark phase. Blood samples were centrifuged immediately $\left(3500 \mathrm{rpm}\right.$ for $25 \mathrm{~min}$ at $\left.4^{\circ} \mathrm{C}\right)$ and extracted plasma was stored at $-80^{\circ} \mathrm{C}$ until assayed for corticosterone using a corticosterone enzyme immunoassay kit (Cayman Chemical Company).

Lenti-shCRFR2 design and production. Four different short hairpin RNA (shRNA) target sequences from the open reading frame of mouse CRFR2 were designed using http://sfold.wadsworth.org software and cloned into shRNA expression cassettes driven by the $\mathrm{H} 1$ promoter in the p156RRLsinPPTCMV-GFP-PREU3Nhe lentiviral construct (kindly provided by Dr. Inder Verma, the Salk Institute for Biological Studies, La Jolla, CA). The recombinant pseudotyped lentiviral vectors were generated by cotransfection of four plasmids into HEK293T cells. The shRNA constructs were generated by synthesis of four different 83-mer oligonucleotides containing a $5^{\prime}$ end including a unique $\mathrm{XbaI}$ restriction site, a stretch of five adenosines as a template for the Pol III promoter termination signal, a 19-nucleotide sense and antisense strands, separated by a 9 nt loop and $20 \mathrm{nt}$ complimentary to the 30 end of the Pol III H1 promoter. The following shRNA oligonucleotides were used (in italics the sense and antisense strands; in bold the nine nucleotide loop): shCRFR2\#1: 5'-CTGT CTAGACAAAAAGCGCACTCCCACTCCCTCTTCTCTTGAA AGAGGG AGTGGGAGTGCGCGGGGATCTGTGGTCTCATACA. shCRFR2\#2: 5'-CTGTCTAGACAAAAACCTACTGCAACACGACCTTTCTCTTGAA AAGGTCGTGTTGCAGTAGGGGGGATCTGTGGTCTCATACA-3-'. shCRFR2\#3: 5'-CTGTCTAGACAAAAAAGGGTCAACTACTCACACTTC TCTTGAA CCCAGTTGATGAGTGTGAGGGGATCTGTGGTCTCATA CA-3'. shCRFR2\#4: 5' -CTGTCTAGACAAAAACCACCTTCATTCTGAGA AATCTCTTGAA TTTCTCAGAATGAAGGTGGGGGGATCTGTGG TCTCATACA-3'.

Validation of lenti-shCRFR2 constructs. HEK293T cells infected with the four different shRNA viruses or with a nonrelated virus as a negative control were transfected with 100 ng myc-tagged CRFR2 expression vector per $35 \mathrm{~mm}$ well plates using polyethylenimine (Sigma-Aldrich). Forty hours after transfection, cells were washed and lysed. Protein concentration was determined using Bradford reagent (Bio-Rad). Proteins were electrophoresed on 10\% SDS-polyacrylamide gel (Bio-Rad) and transferred onto nitrocellulose membranes. Membrane was probed with antibodies-specific for myc raised in mouse (Abcam), washed with TBST, and incubated with peroxidase labeled anti-mouse antibody (GE Healthcare Biotech GE Healthcare Pharmacia). Immunoreactive proteins were visualized using Super Signal West Pico Chemiluminescent substrate (Pierce). Membrane was stripped and reprobed with antibodies directed against the protein kinase PAK, raised in rabbit (Santa Cruz Biotechnology). The relative protein level was determined using the NIH Image 1.63 densitometry software (http://rsb.info.nih.gov/ij/). The ability of the lenti-shCRFR2 vectors to attenuate the CRFR2 functionality was assessed by measuring the CRF-induced cyclic adenosine monophosphate (cAMP) signaling. HEK293T cells infected with the different shRNA viruses or with a nonrelated virus as a negative control were used for cAMP responsive element (CRE) activation studies. Cells were plated in $60 \mathrm{~mm}$ well plates and transfected with $0.13 \mathrm{mg}$ of CRFR1 expression vector, $0.78 \mathrm{mg}$ of luciferase (luc) reporter containing a fragment of the Evxl gene, which contains a potent CRE site (kindly provided by Dr. Marc Montminy, The Salk Institute), and 32 ng of renilla luciferase (ruc) under the promoter of elf2. Twenty-four hours after transfection, cells were harvested using trypsin and replated in a 96-wells plate. Forty hours after transfection cells were treated for $4 \mathrm{~h}$ with vehicle or with different concentrations (6.25-1000 pM) of Ucn2. The cells were harvested and the luciferase reporter activity was assayed as previously described (Kuperman et al., 2011). Transfections were performed at least three times (in 4-6 replicates) for each construct or treatment tested. To correct for variations in transfection efficiencies, luciferase activities were normalized to renilla activity. The ability of the lenti-shCRFR2 vector \#3 to reduce CRFR2 mRNA expression level was further verified using in situ hybridization on brain slices of mice which were unilaterally injected with lenti-shCRFR2 vector \#3 to their lateral septum (injection coordinates: bregma, $+0.14 \mathrm{~mm}$; mediolateral, $+0.5 \mathrm{~mm}$; and dorsoventral, $3.5 \mathrm{~mm}$ ). For CRFR2 in situ hybridization, antisense and sense (control) RNA probes were generated using CRFR $2 \alpha$ cDNA and labeled with DIG11-UTP using a labeling kit (Roche Molecular Biochemicals). In situ hybridization for CRFR $2 \alpha$ mRNAs was performed with the free-floating section method as previously described (Neufeld-Cohen et al., 2010).

Intracerebral injections of lentiviral vectors. Adult (8 weeks) C57BL/6J male mice (Jackson Laboratory) received bilateral stereotaxic injections of lentivirus to the posterior-medial BNST. Mice were injected either with shCRFR2 or control shRNA into the posterior-medial BNST. Mice were anesthetized using $1.5 \%$ isofluorane and were bilaterally injected with a total of $1.5 \mu \mathrm{l}$ of lentiviruses into each side of the BNST. At mediolateral, $+0.65 \mathrm{~mm}$; dorsoventral, $-4.7 \mathrm{~mm}$; and $-0.22 \mathrm{~mm}$ from bregma, $0.75 \mu \mathrm{l}$ were released and then again another $0.75 \mu \mathrm{l}$ was released on the way up at dorsoventral $-4.2 \mathrm{~mm}$. $0.75 \mu \mathrm{l}$ was released mediolateral, $-0.65 \mathrm{~mm}$; dorsoventral, $-4.7 \mathrm{~mm}$; and $-0.22 \mathrm{~mm}$ from bregma, and another $0.75 \mu \mathrm{l}$ was released at dorsoventral $-4.2 \mathrm{~mm}$. Lentiviral injections were conducted using a computer-guided stereotaxic instrument and a motorized nanoinjector (Angle Two Stereotaxic Instrument, myNeurolab), which is fully integrated with the mouse brain Paxinos and Franklin (2003) atlas via a control panel. Mice were given a 2 week period for recovery. Data of mice that were inaccurately injected were excluded from all tests.

Histological and immunohistological analysis. Animals were anesthetized and then perfused with phosphate-buffered $4 \%$ paraformaldehyde. Fixed brains were serially sectioned and confirmation of the accuracy of the injection site was done by immunostaining using biotinylated anti GFP antibody raised in rabbit as primary antibody (Abcam) and streptavidin-conjugated Cy2 anti rabbit as secondary antibody (Jackson ImmunoResearch Laboratories).

BNST mRNA expression array. Agentek Taqman custom made array (Applied Biosystems) was used. Thirty genes of interest were chosen plus two housekeeping genes, Hypoxanthine guanine phosphoribosyl transferase 1 (HPRT1) and ribosomal protein, S18 and run on 96 well plates using Applied Biosystems 7500 thermocycler. Total RNA ( $1 \mu \mathrm{g})$ was used to synthesize template cDNA. Analysis of gene expression was determined by a predefined data analysis template (SA Biosciences) that reported fold change differences and $p$-value for comparisons of PTSD-like versus Resilient mice.

Statistics. One-way ANOVA was performed in all tests or measurements in which all four groups i.e., control, trigger, trauma, and trauma plus trigger were involved. Further planned contrasts were performed between control versus trauma plus trigger, trigger versus trauma plus trigger, and trauma versus trauma plus trigger treatments. In cases where not all groups were significantly different from the trauma plus trigger groups, a Bonferroni correction was performed on the $p$-value of the Student's $t$ test. All other statistical analysis that involved two groups such as PTSD-like versus Resilient used Student's $t$ test to assess significance.

For behavioral results of lentiviral-injected mice, Student's $t$ test was used between control and CRFR2 KD-injected mice. If behavior was compared before and after trauma plus trigger exposure, two-way ANOVA with repeated measures was used with Student's $t$ test post hoc. 
A

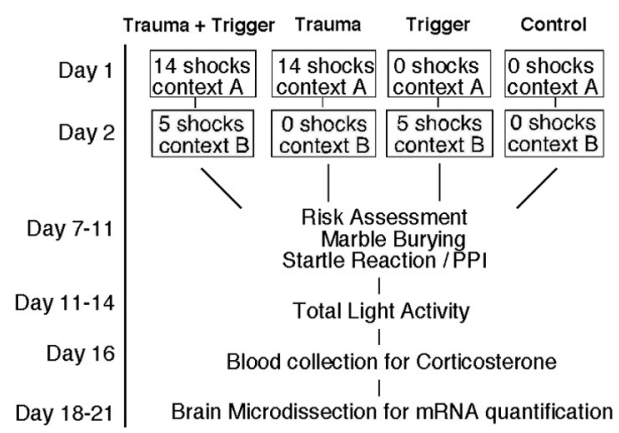

B

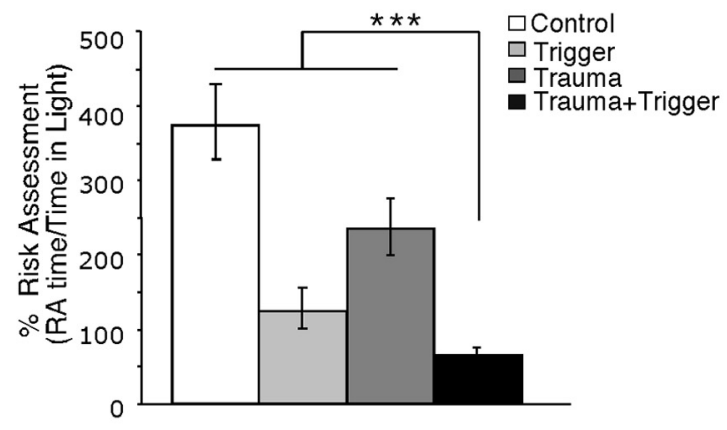

C Latency to Peak Startle Amplitude

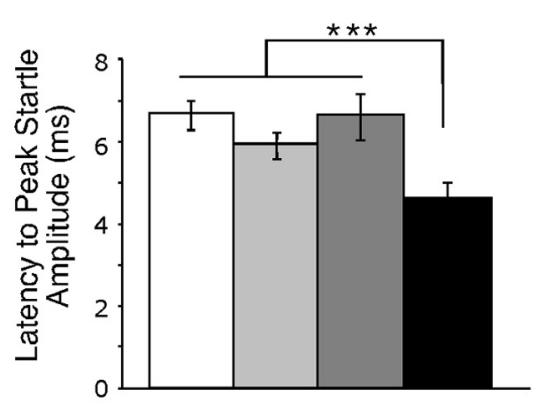

Total Light Locomotor Activity

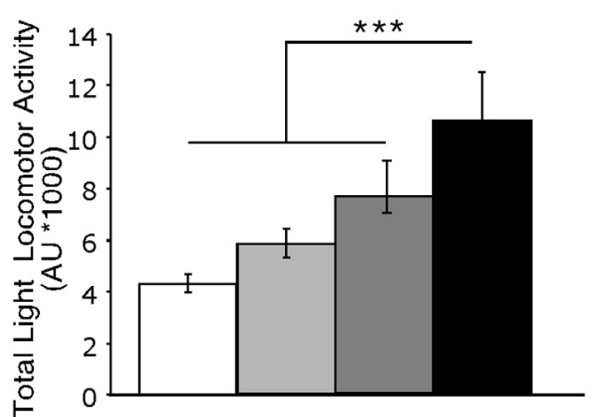

$E$ Locomotor Activity

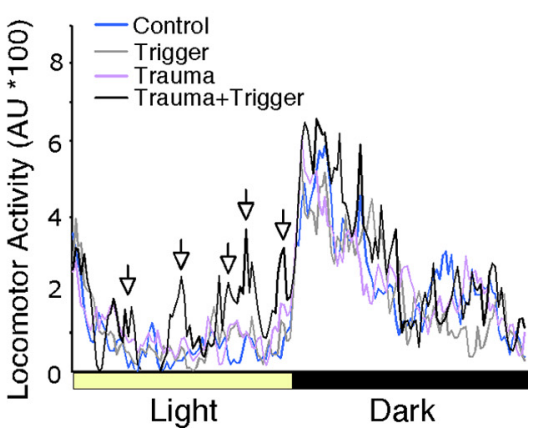

Figure 1. Validation of unique trauma + trigger phenotype. $A$, Timeline of shock exposure as part of trauma plus trigger and control protocols, behavioral tests, and collection of biological samples. $\boldsymbol{B}$, Trauma plus trigger mice show significantly less percentage of time in the light/dark paradigm engaged in risk assessment behavior $\left(F_{(3)}=30.7257, p<0.0001, n=(9-50)\right.$; planned contrasts $\left.F_{(89)}=68.9777, p<0.000000000001\right)$. C, The significantly fastest startle response upon exposure to startle stimulus $\left(F_{(3)}=5.6378, p<0.0015, n=16-30 ;\right.$ planned contrast $F_{(80)}=$ $15.42775, p<0.00018)$. D, Significantly more activity in the nonactive phase of the light/dark cycle $\left(F_{(3)}=5.6378, p<0.0001, n=10-15 ;\right.$ planned contrasts $\left.F_{(52)}=31.7737, p<0.0000007\right)$. $E$, Sample activity in both phases of the light cycle in which trauma plus trigger exposed mice are the most active $\left.{ }^{* * *} p<0.0001\right)$.

Factor Analysis was performed using SPSS software to determine which scores should be given to which tests.

\section{Results}

PTSD-like behavior in mice exposed to trauma plus trigger conditions

The SEFL model is based on the premise that behavioral symptoms of PTSD can be triggered by a mild event if the animal has already been exposed to a "trauma." Usually, the behavioral response of a mouse is proportional to the intensity of the stressor and this should be the case in response to a trauma. However, when a "trigger" follows a trauma then the behavioral response to the trigger more closely mimics an appropriate behavioral response to a trauma despite the lower intensity of the trigger. This is clinically relevant as PTSD patients may experience only one trauma, but exposure to subsequent daily life stressors illicit hyper-responsive stress responses. In our adapted version of this model, mice were phenotyped for PTSD-like behavior in several clinically relevant paradigms after trauma + trigger conditions or appropriate controls.

We tested animals in one of four protocols (Fig. 1A): "Control", in which on day 1 and day 2 animals received no shocks in either context A or B; "Trigger," in which animals received no shocks in context A on day 1 and received 5 shocks in context B on day 2; "Trauma," in which animals received 14 shocks on day 1 in context A and no shocks in context B on day 2; and "Trauma + Trigger" in which animals received 14 shocks on day 1 in context $\mathrm{A}$ and 5 shocks in context $\mathrm{B}$ on day 2 (Fig. $1 A$ ). All animals were then tested in three different paradigms which together comprise PTSD-like attributes: risk assessment behavior, which demonstrates impaired judgment in assessing danger; latency to peak startle amplitude response, which reflects alertness; and locomotor activity in the nonactive phase of the light/dark cycle, of which activity in light reflects sleep disturbances (Fig. $1 A)$. Trauma + trigger exposed mice spend the least amount of time engaged in risk assessment behavior (Fig. $1 B, F_{(3)}=$ 30.7257, $p<0.0001, n=(9-50)$; planned contrasts $F_{(89)}=$ 68.9777, $p<0.000000000001)$; their reaction time to the startle stimulus was significantly faster (Fig. $1 C, F_{(3)}=5.6378, p<$ $0.0015, n=16-30$; planned contrast $F_{(80)}=15.42775, p<$ 0.00018 ), and they showed more activity in the light cycle than any other group (Fig. $1 D, F_{(3)}=5.6378, p<0.0001, n=10-15$; planned contrasts $\left.F_{(52)}=31.7737, p<0.0000007\right)$.

\section{Application of inclusion criterion for PTSD-like versus resilient mice}

Subpopulations of PTSD-like and Resilient mice were extracted from the trauma + trigger exposed group data based on extreme behavior or lack of thereof. Only trauma + trigger mice that were tested in five behavioral tests: percentage risk assessment, latency to peak startle amplitude, and total light activity as before and two additional tests of percentage ppi and marble burying, were subject to inclusion criteria. Ppi and marble burying are clinically relevant tests of sensorimotor gating and hyper vigilance, respectfully. Mice were given a score for each test based on inclusion into lowest $20 \%$ of percentage of risk assessment time, fastest response to startle stimulus, percentage ppi, and upper $20 \%$, of activity in nonactive phase of the dark/light cycle and percentage of marbles buried (Fig. 2A). 
Animals that despite exposure to trauma + trigger conditions showed no extreme behavior in any behavioral paradigms were categorized as resilient. PTSD-like mice show significantly less time engaged in risk assessment behavior (Fig. $2 B, p<0.007$, PTSD-like $n=10$, Resilient $n=12$ ), show a significantly shorter latency to peak startle amplitude (Fig. $2 C, p<0.01$, PTSD-like $n=7$, Resilient $n=13$ ), are significantly more active in the light cycle (Fig. $2 D, p<0.04$, $n=14$ ), show a significantly smaller reduction in response to startle with a prepulse stimulus (Fig. $2 E$ ) in both $74 \mathrm{db}$ range $(p<0.004, n=11)$ and the $82 \mathrm{~dB}$ range $(p<0.008, n=15)$ and a tendency toward significant ppi disruption in the $78 \mathrm{db}$ range $(p<0.07, n=11)$, and finally PTSD-like mice buried a significantly higher percentage of marbles than Resilient mice (Fig. $2 F, p<0.029$, PTSD-like $n=8$, Resilient $n=9$ ). Baseline startle responses were not significantly different between groups. PTSD-like had an average startle of $115.1 \pm 17.4 \mathrm{~g}$ and Resilient mice had $113.9 \pm 8.2 \mathrm{~g}$.

\section{HPA axis alterations in PTSD-like versus Resilient mice}

Basal, stress-induced and recovery corticosterone levels were measured in all four behavioral protocols two and a half weeks after the start of the experiment, and revealed no difference in corticosterone levels (Fig. 3A, $n=7-9$ ). Upon application of inclusion criterion, PTSD-like mice show attenuated stress-induced corticosterone levels (Fig. 3B, one-way ANOVA with test for repeated measures $F_{(3)} 3.7633, p<0.01$ reveals a significant interaction of time $\times$ treatment; Student's $t$ test post hoc reveals $p<0.001$ for $25 \mathrm{~min}$ time point, $n=10$ ). To further explore at what level the alteration in the HPA axis may have occurred, we assessed the glucocorticoid receptor (GR) mRNA levels in the ventral subiculum of the hippocampus (Fig. 3C) as well as CRF mRNA levels (Fig. 3D) and AVP mRNA levels (Fig. $3 E$ ) in the paraventricular nucleus of the hypothalamus. mRNA quantification of the GR in the ventral subiculum show significant upregulation ( $p<0.04, n=11-12$ ) while no differences are observed in either CRF mRNA or AVP mRNA between PTSD-like and Resilient mice.

BNST-CRFR2 is significantly upregulated in PTSD-like mice Due to the behavioral and physiological phenotype of the trauma + trigger exposed mice, we quantified the mRNA levels of selected CRF family members using real-time PCR in brain centers related to initiation and processing of stress response and associated anxiety centers. Of the all the brain areas, the BNST appeared the most sensitive to changes in the CRF system in response to trauma + trigger exposure. In the BNST, CRFR2 mRNA levels (Fig. $4 A$ ) of the trauma + trigger group were significantly upregulated, nearly three-fold, over all other control groups $(n=$ $8-9, F_{(3)}=4.8579, p<0.0007$ with planned contrasts, $F_{(29)}=$ $13.6238, p<0.0009)$. Furthermore, after application of inclusion criterion, PTSD-like mice revealed significant upregulation of CRFR2 mRNA—nearly four-fold higher than resilient mice, which closely resembles CRFR2 mRNA levels of controls (Fig. $4 A$ ) (PTSD-like $n=5$, Resilient $n=4 p<0.007$ ). In contrast, CRFR1 mRNA levels showed a trend toward downregulation of CRFR1 mRNA levels. CRFR1 mRNA levels observed in the trauma + trigger group compared with the nonshocked controls were significantly lower using Bonferroni correction (Fig. $4 B$, $p<0.001, n=9-12)$. CRF mRNA levels rose in the trauma plus trigger group and after Bonferroni correction (Fig. $4 C, p<0.01$, $n=7-10$ ) had a tendency toward higher levels than the trauma group alone. Neither CRFR1 nor CRF mRNA levels were distinct between subpopulations of PTSD-like and Resilient mice. These results may suggest that the long-term behavioral effects observed following exposure to trauma + trigger conditions are mediated via the BNST-CRFR2 system. Interestingly, no differences in either CRFR1 or CRF mRNA levels were observed in the amygdala between the groups (data not shown).

\section{Establishment of lentiviral-shRNA construct design for CRFR2 knockdown}

Since we observed that robust changes in BNST-CRFR2 levels coincide with susceptibility to PTSD, we sought to manipulate the endogenous levels of CRFR2 specifically within the BNST of adult mice and determine its effect on the susceptibility to PTSDlike behavior. Four different shRNA target sequences from the open reading frame of mouse CRFR2 were cloned into lentiviral shRNA expression cassettes driven by the $\mathrm{H} 1$ promoter, and lentiviruses were produced (Fig. 5A). To confirm the ability of the shCRFR2 viruses to knockdown levels of CRFR2, HEK293T cells were infected with the lentiviruses expressing the different shRNAs, thus generating a stable cell line for each CRFR2-shRNA expressing construct. These stable cell lines were transfected with plasmids expressing mouse CRFR2 carrying a myc tag, which we constructed for 
A
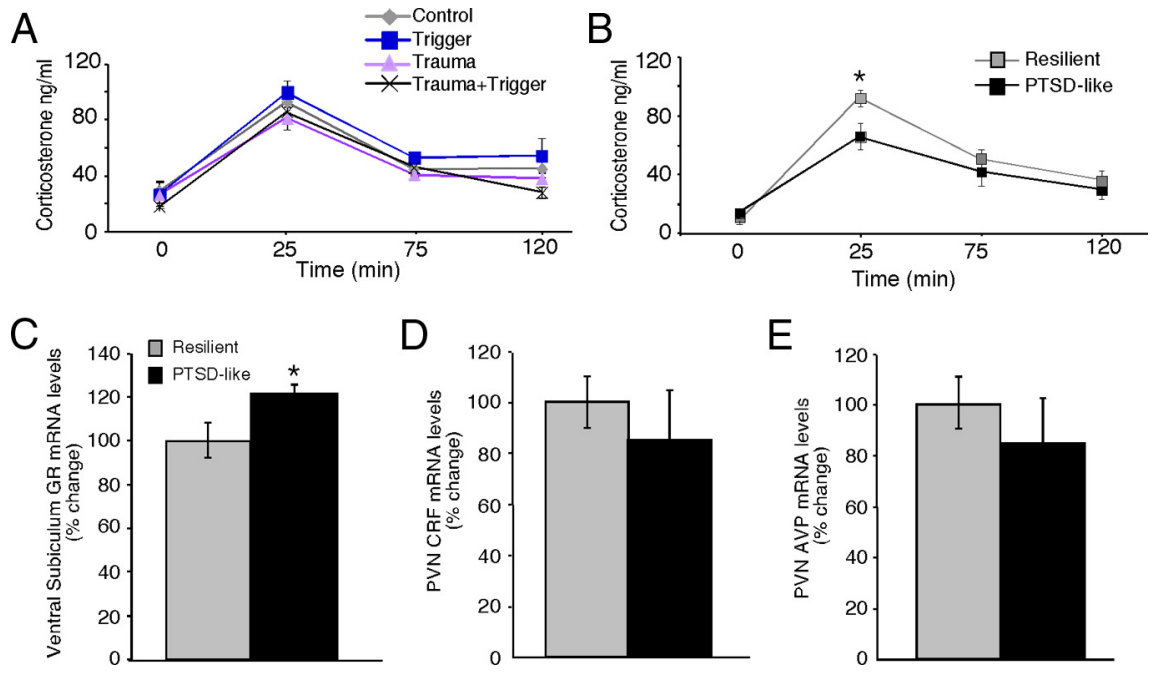

Figure 3. HPA axis alterations in PTSD-like and Resilient groups of mice. $A$, There is no difference in corticosterone levels between trauma plus trigger mice and all other behavioral controls. $\boldsymbol{B}$, When PTSD inclusion criteria is applied to trauma plus trigger exposed mice, PTSD-like mice show an attenuated stress-induced response levels (one-way ANOVA with test for repeated measures $F_{(3)} 3.7633, p<0.01$ reveals a significant interaction of time $\times$ treatment, Student's $t$ test post hoc reveals $p<0.001$ for 25 min time point, $n=10)$. $C-E$, "PTSD-like" mice also show significantly elevated GR mRNA levels in the ventral subiculum $(p<0.04, n=11, n=12)(\boldsymbol{C})$ and show no significant differences in CRF (D) or AVP (E) mRNA levels in the periventricular nucleus of the hypothalamus $\left({ }^{*} p<0.001\right)$.
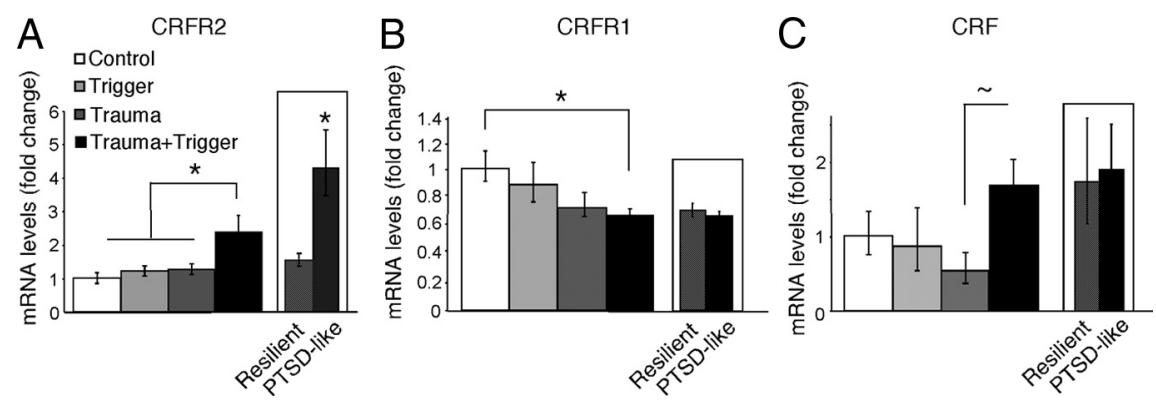

Figure 4. mRNA quantification of BNST CRF system $(A)$ BNST CRFR2 mRNA levels are significantly upregulated, nearly threefold, over all other control groups $\left(n=8-9, F_{(3)}=4.8579, p<0.0007\right.$; with planned contrasts, $\left.F_{(29)}=13.6238, p<0.0009\right)$. PTSD-like mice have significant upregulation of CRFR2 mRNA — nearly four-fold higher than resilient mice, which closely resemble CRFR2 mRNA levels of controls ( $p<0.007$ PTSD-like $n=5$, Resilient $n=4)$. B, BNST CRFR1 mRNA levels observed in the trauma plus trigger group compared with the nonshocked controls were significantly lower $(p<0.001, n=9-12)$. No differences were observed between PTSD-like and Resilient mice. C, CRF mRNA levels were significantly upregulated in the trauma plus trigger group versus trauma group alone $(p<0.01, n=7-10)$ but no difference were observed between subpopulations of PTSD-like and Resilient mice $\left({ }^{*} p<0.001, \sim p<0.07\right)$.

this purpose. Determining levels of CRFR2 protein by Western blotting with a myc-specific antibody showed that shCRFR2 lentiviruses numbers 1, 2, and 3 showed reduced levels of CRFR2 as compared with cells infected with a nonrelated virus (Fig. 5B). shCRFR2-\#2 and shCRFR2-\#3 reduced expression of CRFR2 protein by $\sim 80 \%$ (Fig. 5B). To further determine whether knockdown of mRNA and protein levels is also reflected in decreased functionality of the receptor, we studied the activation of cAMP signaling in infected HEK293T cells. shCRFR2-\#2 and shCRFR2-\#3 stably expressing cells were transfected with the EVX1-CRE-Luciferase construct (kindly provided by Dr. Marc Montminy, The Salk Institute), and luciferase levels, as a function of cAMP signaling activation, were measured following $3 \mathrm{~h}$ treatment with different concentrations of Ucn2 (Fig. 5C). Both shRNAs showed significant inhibition of cAMP signaling, when compared with cells infected with a nonrelated virus. To test the ability of shCRFR2 to knock down the expression of CRFR2 in vivo, mice were injected unilaterally into the lateral septum, which express high levels of CRFR2, with lentiviruses expressing shCRFR2\#3 (Fig. 5D). Following a week recovery period, mice were anesthetized, perfused, and fixed brains were examined to confirm the infected sites. Coronal brain sections were analyzed using in situ hybridization, with mouse CRFR2-specific probe from control or unilaterally injected mice. The results showed a significant reduction at the lateral septum CRFR2 mRNA levels in shCRFR2-injected brains. These data demonstrate our ability to perform the precise delivery of lentiviruses to specific brain nuclei and to manipulate the expression levels of CRFR2.

\section{BNST-specific CRFR2 knockdown reduces susceptibility to $\mathrm{PTSD}$}

After validation of the lentiviruses, 24 mice were injected with either shCRFR2 viruses $(n=13)$ or control viruses $(n=$ 11 ) into the posterior medial BNST as shown in Figure 6, $A$ and $B$, in a schematic from Paxinos and Franklin (2003) mouse brain atlas. Figure $6, C$ and $D$, show GFP stainings. GFP is coexpressed with the shRNA sequences of both the CRFR2 and control lentiviruses. Figure 6, E and $F$, show a GFP staining of a unilaterally CRFR2-injected mice and in situ hybridization for BNST CRFR2, illustrating the efficacy of the virus in vivo. To characterize the effect of the CRFR2 knockdown (KD) and then separately assess its added effect on susceptibility to PTSD, we first tested the mice in the five behavioral paradigms as described above. All mice were then exposed to trauma + trigger conditions, once again tested behaviorally, and inclusion criteria were applied. There were no significant differences in any of the behavioral tests before the trauma plus trigger exposure (Fig. 6G-K, left bars) with an exception of a strong tendency of a lower percentage ppi (Fig. 6G, left bars, $p=0.059$, Student's $t$ test) in CRFR2 KD mice. However, following trauma + trigger conditions, this behavior was completely reversed $\left(F_{(1)}=5.0388, p=0.033\right)$ in that control-injected mice had no reduction in startle response to prepulse $(p=0.0372$, Student's $t$ test post hoc), revealing the protective effect of the BNST-CRFR2 KD on prepulse inhibition (Fig. 6G, right bars). BNST-CRFR2 KD mice also showed a tendency toward increased risk assessment (Fig. $6 H$, right bars, $p=0.10$, Student's $t$ test) and toward a reduction in the number of marbles buried (Fig. $6 \mathrm{~J}$, right bars, $p=0.10$, Student's $t$ test), while no changes were observed with respect to latency to peak startle amplitude (Fig. $6 I$ ) and locomotor activity in the light (Fig. $6 \mathrm{~K}$ ). Interestingly, BNST-CRFR2 KD mice had significantly higher corticosterone levels basally after trauma + trigger exposure than controls (Fig. $6 L, p=0.027)$. While in the validation of the model we demonstrated lower peak corticosterone levels, here we show lower basal corticosterone levels. This may suggest that reduced BNST- 
A

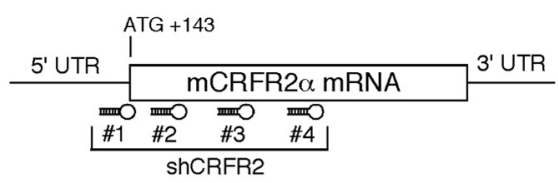

B
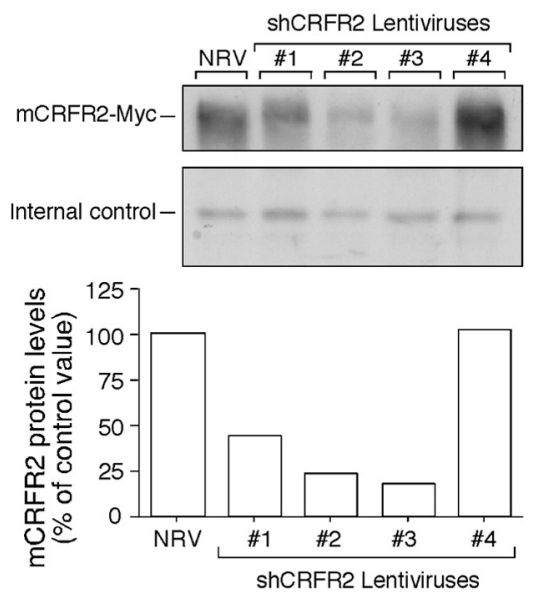

C

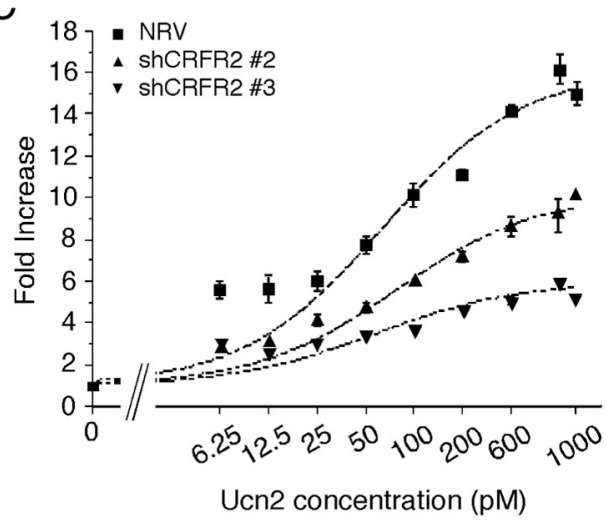

D

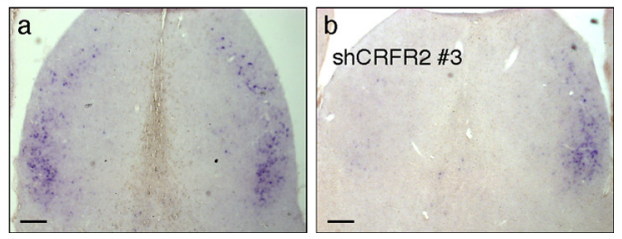

Figure 5. Lentiviral-based system for site-specific knockdown of CRFR2. A, Four different shRNA target sequences from the open reading frame of the mouse CRFR2 gene were designed. B, Western blot analysis followed by densitometry measurements show the ability of viruses \#2 and \#3 to reduce levels of CRFR2 expression in CRFR2 HEK293T transfected cells. C, The ability of shCRFR2 to decrease the functionality of the receptor was confirmed by assessing CAMP activation, after $4 \mathrm{~h}$ treatment with different concentrations of Ucn2. D, Site-specific delivery of shCRFR2\#3 into the lateral septum. Representative in situ hybridization images of coronal brain sections of control (left) or unilaterally injected (right) mouse brain.

CRFR2 levels may protect against susceptibility to PTSD-like behavior via high basal corticosterone levels. In addition, exposure to trauma + trigger itself significantly reduced restraint stressinduced corticosterone levels (Fig. $6 L, F_{(1)}=4.0198, p=0.0127$ ); specifically, BNST-CRFR2 KD mice had a significant reduction before and after trauma + trigger exposure $(p=0.007)$. In addition, an interaction of virus and exposure revealed that peak corticosterone levels of control mice were significantly higher than BNST-CRFR2 KD-injected mice $\left(F_{(1)}=2.6203, p=0.0048\right)$ after trauma + trigger exposure. Of the BNST-specific CRFR2 KD mice, only $9 \%$ showed PTSD-like symptoms while $23 \%$ of controls developed PTSD-like symptoms after application of inclusion criteria (Fig. $6 \mathrm{M}$ ). There was a rate of $16 \%$ PTSD-like behavior in the population of mice. Therefore, preemptive reduction of CRFR2 levels in the BNST reduces susceptibility to PTSDlike symptoms after exposure to a trauma + trigger.

\section{BNST mRNA expression profile implies reduced transcription in PTSD-like mice}

To determine whether the observed behavioral and neuroendocrine differences between the PTSD-like and Resilient mice were also reflected in the gene expression profile of the BNST, we evaluated the expression levels of selected BNST genes in both groups $(n=5-6)$. The expression levels of 30 stress-related and housekeeping genes associated with BNST functions were assessed using a custom-made real-time PCR array (Fig. 7A).

Collectively, the results of the BNST gene regulation profile suggest an attenuated transcription in the PTSD-like mice compared with the resilient group.

As shown in Figure 7B, most of the genes in the PTSD-like mice revealed lower expression levels, while the mRNA of the following eight genes were significantly downregulated: Adra2a $(p<0.0327)$, Adrbkl $(p<0.0263)$, Fkbp5 $(p<0.0422)$, Gabra2 $(p<0.0323)$, Gabra3 $(p<0.0269), H \operatorname{trla}(p<0.0304), H \operatorname{tr} 2 c(p<0.032)$, and $H \operatorname{tr} 7(p<0.022)$. From these data, we hypothesized that alterations in chromatin remodeling may cause transcriptional attenuation in the BNST of PTSD mice and therefore sought to quantify mRNA levels of the deacetylation enzymes, HDAC2 and HDAC5, as well as mRNA of methylation enzymes, DNMT1, DNMT3a, and DNMT3b. The HDAC5 mRNA levels were significantly upregulated in trauma + trigger mice (Fig. $7 C, F_{(3)}=5.7891, p<0.002, n=$ 5-27; planned contrast $\left.F_{(44)}=16.915837, p<0.000168\right)$ and were two-fold higher in PTSD-like compared with Resilient mice $(p<$ 0.048 ). Neither HDAC2 (Fig. $7 D$ ) nor any of the methylation enzymes showed any significant changes (Fig. $7 E-G$ ).

\section{Discussion}

In this study we aimed to unravel the brain areas and genes responsible for the disruption of recovery in a PTSD-like animal model. We show that CRFR2 mRNA upregulation in the BNST coincides with PTSD-like symptoms of hyperarousal, hypervigilance, impairment in attention, engagement in risky behaviors, and difficulty sleeping as well as with attenuated glucocorticoid levels and chromatin remodeling of the BNST. We further show that knockdown of CRFR2 in the posterior medial BNST of adult mice reduces susceptibility to PTSD-like behaviors.

A reduction in BNST CRFR2 levels can specifically reverse ppi impairment, a measure of sensorimotor gating but also a test that requires attentional processes, after trauma exposure. While the DSM IV (American Psychiatric Association, 1994) for PTSD includes exaggerated startle, Grillon et al. (1996) reports normal acoustic startle in the response of Vietnam veterans, but abnormally low ppi compared with civilian controls. PPI in animal models of PTSD demonstrate impaired ppi $24 \mathrm{~h}$ after predator exposure as well as after intracerebroventricular injections of supraphysiological levels of CRF, but not after footshock (Bakshi et al., 2011). Additionally, CRFR2 knock-out mice show overall lower startle (Risbrough et al., 2009) and antagonists to CRFR2 coadministered intracerebroventricularly with physiological levels of CRF show enhanced ppi (Risbrough et al., 2004). Here, we demonstrate that prepulse inhibition is highly regulated by CRFR2 in the BNST.

The PTSD-like mice also show risk assessment patterns consistent with an immediate or imminent danger in the face of a 
A

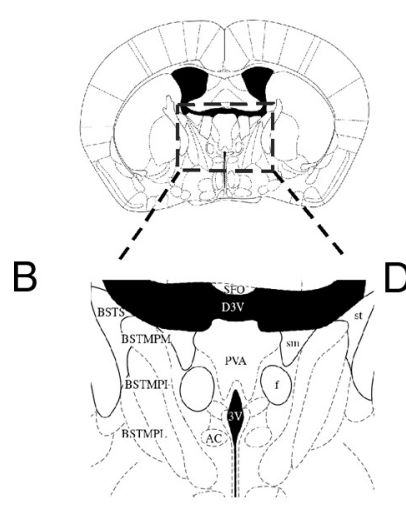

C
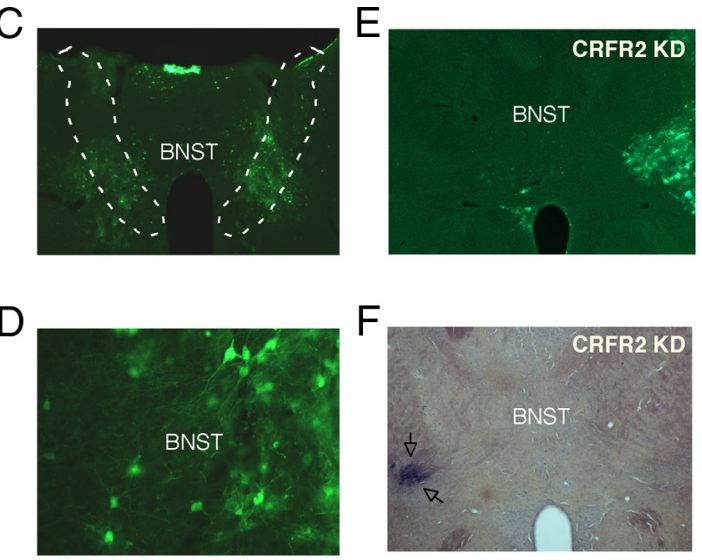

$\mathrm{G}$

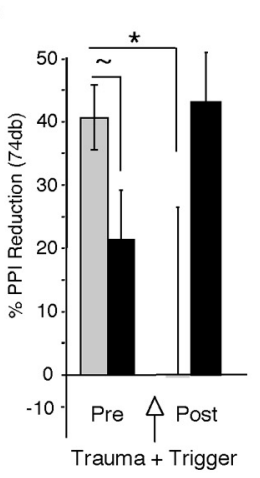

$\mathrm{H}$
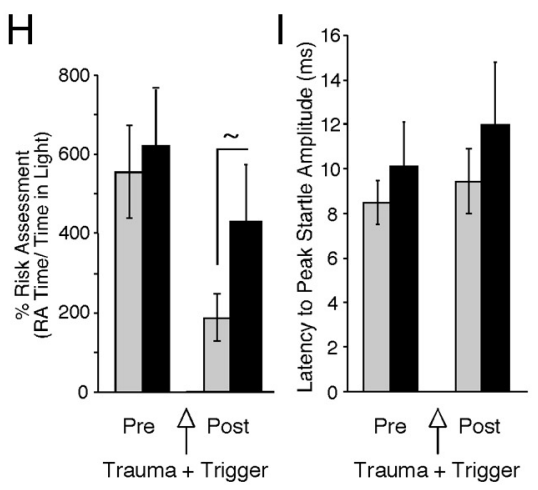

$J$
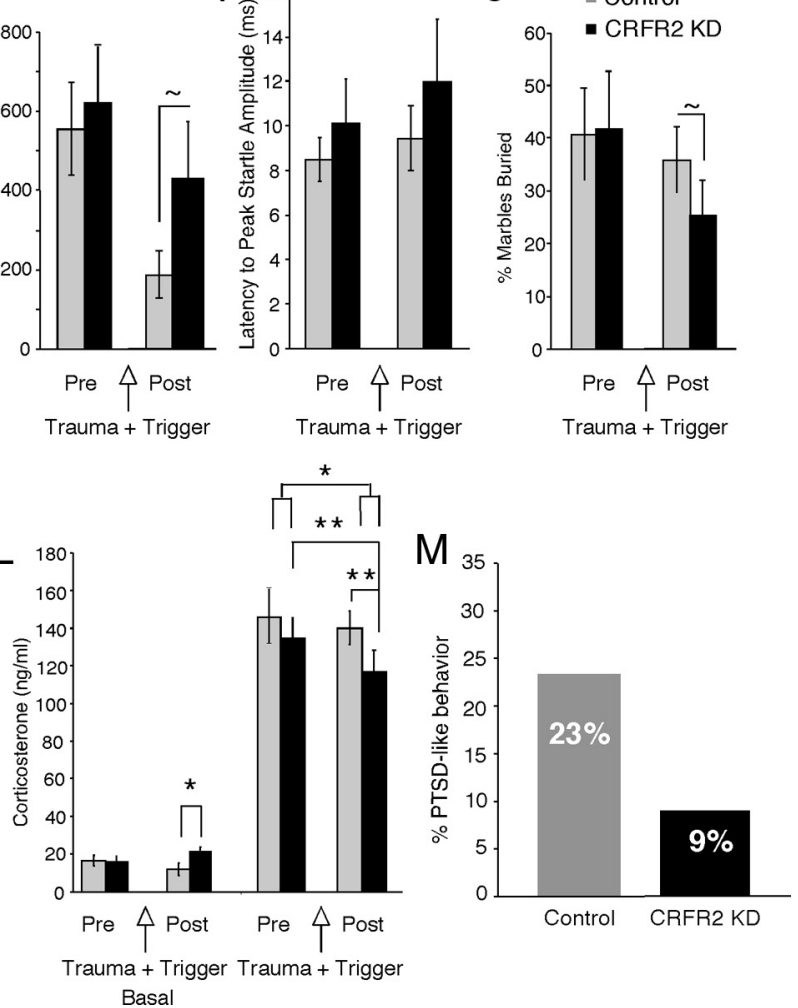

Figure 6. Lentivirus validation, injection, and results. $A$ and $B$ illustrate injection site, and C shows confirmation of BNST-specific knockdown of CRFR2 via GFP immunostaining. $\boldsymbol{D}$ shows infected neurons at site of injection. $\boldsymbol{E}$, A GFP staining of a unilaterally CRFR2-injected mice and in situ hybridization for BNST CRFR2 $(\boldsymbol{F})$, illustrating the efficacy of the virus in vivo. G, Percentage ppi was reversed before and after trauma + trigger conditions $\left(F_{(1)}=5.0388, p=0.033, n=11-13\right)$ in that control-injected mice after trauma + trigger exposure had no inhibition in startle response to prepulse, although before exposure they had the most inhibition ( $p=0.0372$ ). $\boldsymbol{H}$, CRFR2 KD mice also showed a tendency toward increased risk assessment $(p=0.10) . \boldsymbol{I}$, No changes were observed with respect to latency to peak startle amplitude. $\boldsymbol{J}$, There was a tendency toward a reduction in the number of marbles buried $(p=0.10$ ), while no effect was observed on locomotor activity in the light $(\boldsymbol{K})$. $\boldsymbol{L}$, Stress-induced corticosterone levels in all mice were significantly reduced following trauma plus trigger exposure $\left(F_{(1)}=4.0198, p=0.0127\right)$ and in CRFR2 mice $(p=0.007)$ as well, but not in control mice. Also, peak corticosterone levels of control mice were significantly higher than CRFR2 $\mathrm{KD}$-injected mice $\left(F_{(1)}=2.6203, p=0.0048\right)$ after trauma + trigger exposure. Basally after trauma + trigger exposure, CRFR2 KD mice had higher corticosterone levels $(p=0.027)$. $\boldsymbol{M}$, of the CRFR2 knockdown mice, only $9 \%$ showed PTSD-like symptoms while $23 \%$ of controls developed PTSD-like symptoms after application of inclusion criteria $\left({ }^{*} p<0.05\right.$, ${ }^{* *} p<0.01, \sim p<0.10$ ).

predator and not to an uncertain potential for risk. Mice normally engage in oriented information-gathering scanning from place of concealment and increases in stretch attend posture (Blanchard and Blanchard, 1989; Blanchard et al., 1990) in the absence of a predator, but in the presence of a predator this activity is reduced in favor of quick flight. Increased risk assessment is also associated with reduced anxiety (Adamec and Shallow, 1993) and CRFR1 blockade reverses reduction in risk assessment after predator stress exposure (Adamec et al., 2010). In PTSD patients this dysfunction often manifests itself as paranoia (Campbell and Morrison, 2007) and risky behavior demonstrated by high incidences of violence, drug abuse, or suicide (Panagioti et al., 2009; Najt et al., 2011). In the presence of BNST-CRFR2 KD and exposure to trauma, mice exhibit increased risk assessment, reduction in impaired judgment, and reduced marble-burying behavior, reducing symptoms of hypervigilance.

The current PTSD-like mouse model is the first to incorporate problematic sleep/ wake disturbances. Most patients will reach a clinical setting initially due to insomnia or disturbing nightmares, which to date have no specific cure. In this study, we show that during nonactive phases of the circadian cycle, PTSD-like mice are more active. Previous studies report an interaction between PTSD and decreased delta quantitative, nonREM (NREM) sleep (Neylan et al., 2003; Woodward et al., 2000). Evidence from mouse studies also supports the hypothesis that stressful experiences and changes in the HPA axis modify NREM or REM sleep. C57BL/6 mice show decreases in NREM sleep in response to intracerebroventricular injections of CRF that are reversed by astressin (Sanford et al., 2008). Considering that BNST-CRFR2 KD did not reverse these effects, it is possible that features of hyperarousal may also be mediated by altered noradrenergic input, CRFR1 or CRF itself.

Additionally, our model coincides with attenuated corticosterone levels as consistent with the literature on HPA axis alterations in PTSD of hypocortisolemia (Mason et al., 1986) (for review, see Yehuda, 2009). While many of the human studies report low basal cortisol levels, our model attenuates stress-induced corticosterone levels, and BNST-CRFR2 knockdown mice have higher basal corticosterone levels after trauma plus trigger exposure, possibly protecting them from PTSD-like behavior. Future studies may benefit from also studying HPA responses at earlier peak time points. Considering that manipulation of the BNST effects corticosterone levels, that PTSD patients also have blunted ACTH (Yehuda et al., 2004), and that our data indicate that at the level of the PVN there is no difference in mRNA levels of CRF or AVP, we suggest the source of corticosterone regulation after trauma is further upstream to the pituitary and PVN. The BNST is a possible candidate due to its already known role in long-term reactions to stressors and associated anxiety (Davis et al., 2010, Liberzon et al., 1999). 
A

\begin{tabular}{|c|c|c|}
\hline \multirow[b]{2}{*}{ Symbol } & $\begin{array}{c}\text { Fold } \\
\text { Difference }\end{array}$ & t-TEST \\
\hline & \begin{tabular}{|c|}
$\begin{array}{c}\text { PTSD Sample } \\
\text { /Resilient } \\
\text { Sample }\end{array}$ \\
\end{tabular} & $P$ value \\
\hline Adra1b & -1.21 & 0.6000 \\
\hline Adra2a & -1.45 & 0.0327 \\
\hline Adra2c & -1.29 & 0.4028 \\
\hline Adrb1 & -1.38 & 0.2313 \\
\hline Adrb2 & -1.11 & 0.5597 \\
\hline Adrbk1 & -1.34 & 0.0263 \\
\hline Bdnf & 1.08 & 0.9106 \\
\hline Comt1 & -1.35 & 0.2210 \\
\hline Crhbp & -1.10 & 0.6088 \\
\hline Crh & 1.05 & 0.9005 \\
\hline Drd1a & -1.67 & 0.1402 \\
\hline Drd2 & -1.68 & 0.2011 \\
\hline Fkbp5 & -1.36 & 0.0422 \\
\hline Gabra2 & -1.36 & 0.0323 \\
\hline Gabra3 & -1.34 & 0.0269 \\
\hline Gabra5 & -1.33 & 0.0641 \\
\hline Gabrd & -1.57 & 0.1968 \\
\hline Galr1 & -1.26 & 0.0906 \\
\hline $\mathrm{Htr} 1 \mathrm{a}$ & -1.33 & 0.0304 \\
\hline $\mathrm{Htr} 2 \mathrm{a}$ & -1.21 & 0.3353 \\
\hline $\mathrm{Htr} 2 \mathrm{c}$ & -1.37 & 0.0312 \\
\hline $\mathrm{Htr} 7$ & -1.30 & 0.0122 \\
\hline $\mathrm{Npy}$ & -1.40 & 0.2224 \\
\hline $\mathrm{Nr3c1}$ & -1.24 & 0.1190 \\
\hline $\mathrm{Nr} 3 \mathrm{c} 2$ & -1.30 & 0.1385 \\
\hline Oprm1 & -1.29 & 0.0519 \\
\hline Oxt & -1.40 & 0.6765 \\
\hline $\begin{array}{l}\text { Slc6a2 } \\
\text { Slc6a3 }\end{array}$ & $\begin{array}{c}-2.92 \\
1.29\end{array}$ & $\begin{array}{l}0.0870 \\
0.3748\end{array}$ \\
\hline
\end{tabular}

B
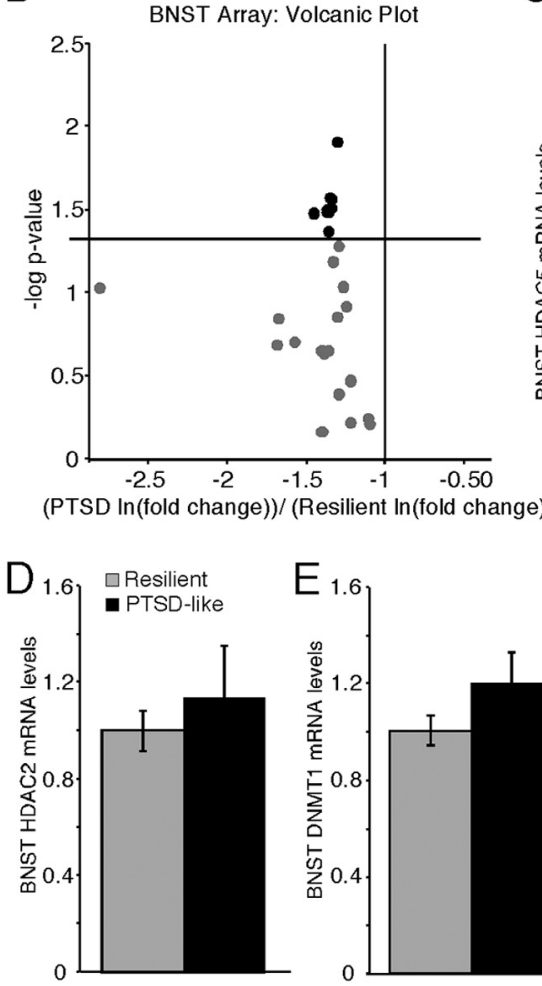

C
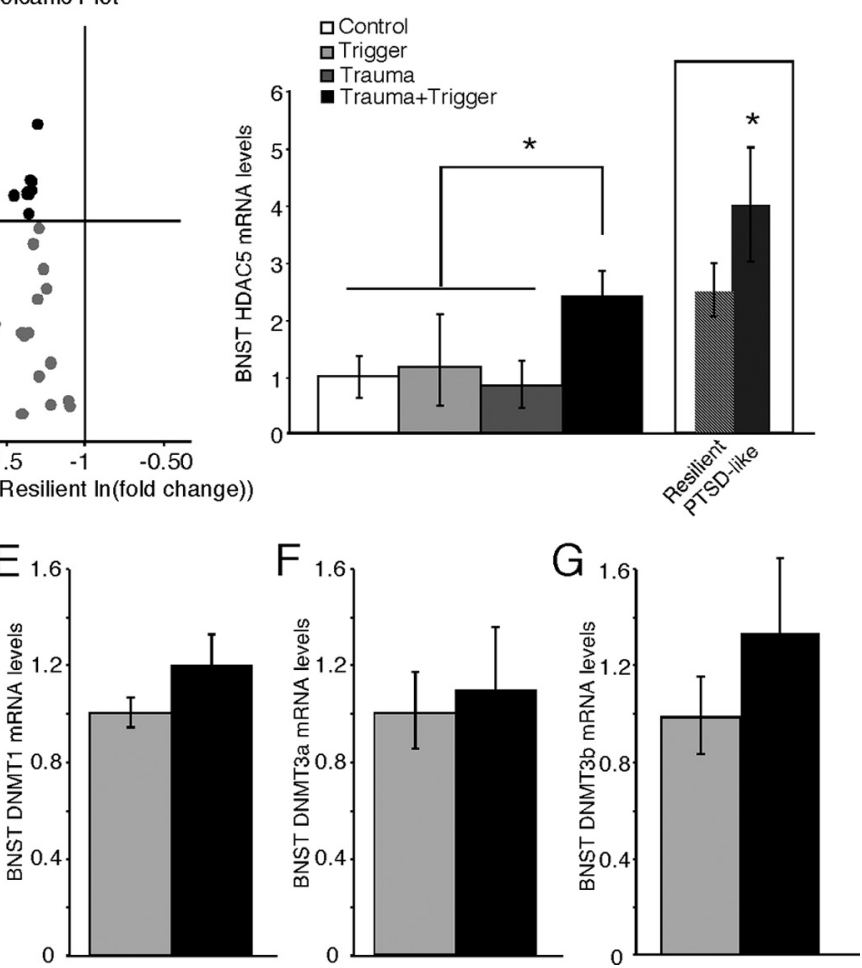

Figure 7. BNST mRNA expression array. $\boldsymbol{A}$, Table showing fold differences and $p$-values of all genes in array. $\boldsymbol{B}$, Volcanic plot illustrating eight significantly downregulated genes $A d r a 2 a(p<$ 0.0327), Adrbk1 ( $p<0.0263), F k b p 5(p<0.0422)$, Gabra2 $(p<0.0323), G a b r a 3(p<0.0269), H \operatorname{tr} 7 a(p<0.0304), H \operatorname{tr} 2 c(p<0.032)$, and Htr7 ( $p<0.022)$ and a general trend toward downregulation. $C$, HDAC5 is significantly upregulated in trauma + trigger mice $\left(F_{(3)}=5.7891, p<0.002, n=5-27\right.$; planned contrast $\left.F_{(44)}=16.915837, p<0.000168\right)$ and PTSD-like mice have significantly higher mRNA levels than resilient mice $(p<0.048)$. D-G, Neither HDAC2 nor any of the methylation enzymes (DNMT1, DNMT3a, DNMT3b) showed any significant changes $\left({ }^{*} p<0.05\right)$.

PTSD-like mice also demonstrated increased GR mRNA in the ventral subiculum (vSUB) of the hippocampus, which contains glutamatergic projections to the medial nuclei of the BNST (Cullinan et al., 1993), and in turn the BNST sends GABAergic projections to the mpPVN. Choi et al. (2008a,b) demonstrate that the posterior BNST and not anterior BNST is capable of attenuating a rise in corticosterone in response to acute stress. Additionally, the circuit of vSUBposterior medial BNST (pmBNST)-PVN inhibits the HPA axis, specifically in response to psychogenic stress (Ulrich-Lai and Herman, 2009). Together, these findings place the CRFR2 in the posterior medial BNST as a potential candidate for controlling the enhanced negative feedback exhibited by PTSD patients.

Cellularly, the connection between the glucocorticoid receptor of the VSUB via excitatory glutamatergic connections and the inhibition of the PVN might also spotlight FKBP5, in addition to CRFR2. FKBP5 regulates GR binding and translocation by binding and initiating intracellular feedback on the GR system (Gillespie et al., 2009). An increase in GR cellular pathways via FKBP5 may also prevent excessive negative feedback in response to traumatic events. FKBP5 SNPs are also associated with increased risk of PTSD after childhood trauma (Binder et al., 2008; Nelson et al., 2009).

The role of CRFR2 in the hippocampus has been shown to be critical to activation of MAPK pathway after immobilization stress and subsequent fear conditioning. Intrahippocampal blockade of CRFR2 prevented MAPK pathway activation and reduced freezing (Sananbenesi et al., 2003). Increased GR in the vSUB may therefore regulate the cellular cascade of memory enhancement via FKPB5, in consortium with CRFR2 activated MAPK-dependent pathways and enhanced Egr-1 nonMAPK- dependent signaling (Revest et al., 2005) in the hippocampus or BNST before the signal is passed on to the PVN allowing for enhancement of stress-related memories.

Increased sympathetic activity, perhaps the least controversial physiological change in PTSD and the effectiveness of treatments including clonidine, the noradrenergic $\alpha 2$-antagonist, demonstrate the beneficial effects of mitigating the noradrenergic response (Fink, 2011). While the BNST receives noradrenergic stimulus from A1/A2 cell bodies, the locus coreleus projects mainly to the amygdala (Forray and Gysling, 2004). Since the amygdala itself has substantial innervation to the BNST and not the PVN, its role in PTSD may be to fine tune the BNST-mediated stress response via changes in noradrenergic, GABA, and glutamate systems and not in CRF-related systems changes. While Ponomarev et al. (2010) show in the original SEFL model, in rats 3 weeks after exposure to trauma and trigger, a general trend toward downregulation of the amygdalar mRNA expression profile, their main findings reflect transciptome shifts toward hyperresponsiveness of the amygdala via decreased GABA tone, enhanced glutamatergic regulation, and changes in transposable elements and chromatin modulators.

A critical question in the neurobiology of PTSD is whether the pathology arises in the brain due to an exaggerated stress response that remains active enough to meet DSM criteria 1 month after exposure to trauma, or if the shutting down of the stress response fails to occur over the long-term. While the CRF/CRFR1 interaction may play an immediate role in responding to a traumatic event and in consolidation of the trauma, we suggest here that its activation alone is inadequate to explain the long term 
effects of PTSD. Since indeed none of the protocols in our model showed significant long-term changes in CRFR1, we suggest that the initiation of the stress response has indeed subsided. In fact, Thoeringer et al. (2012) show that traumatic memories in the hippocampus can be reversed by CRFR1 antagonists only within the first week after the trauma. So if CRFR1 activity does not regulate long-term responses to PTSD and PTSD is a pathology that can last for years, then the shutting off of the response to the trauma must be impaired. CRFR2 knock-out mice are commonly associated with anxiety-like states (Bale et al., 2000; Kishimoto et al., 2000), implying the opposing role of CRFR2 to CRFR1 in coping after a stressor. In addition, CRFR2 levels regulate downstream genes to return to homeostasis (Neufeld-Cohen et al., 2010). However, optimal levels of CRFR2 may be critical for appropriate coping in response to a traumatic event. Low levels and high levels of CRFR2 prevent proper return to homeostasis in response to stress.

PTSD is therefore not a disease of stress sensitivity, but rather a disease of coping. Dramatic changes in the CRFR2 system are at the forefront of the neuropathology of PTSD and can explain the long duration of the disorder. Only animals with exposure to trauma plus trigger conditions show dramatic elevations in CRFR2 mRNA levels long-term. In addition, only those animals who were the most behaviorally extreme showed the most dramatic rises in CRFR2 mRNA in the BNST. In our model we see that in response to a traumatic event, and thus a heavy allostatic load, the body may overcompensate its activation of coping to the point that extremely high levels of BNST CRFR2 cause enhanced negative feedback, excessive downregulation of downstream genes, and even enhanced chromatin packing, further shifting away from allostasis to pathology. In this case the individual will be incapable of initiating an appropriate stress response to the next upcoming stressor. The apparent readiness for a new stressor seen in the clinical setting manifesting in alertness, vigilance, or aggressiveness is futile as the body can now only respond excessively to minor stressors and is dysfunctional in new moderate to high stress real-life situations.

\section{References}

Adamec RE, Shallow T (1993) Lasting effects on rodent anxiety of a single exposure to a cat. Physiol Behav 54:101-109.

Adamec R, Fougere D, Risbrough V (2010) CRF receptor blockade prevents initiation and consolidation of stress effects on affect in the predator stress model of PTSD. Int J Neuropsychopharmacol 13:747-757.

American Psychiatric Association (1994) Diagnostic and statistical manual of mental disorders (DSM IV). American Psychiatric: Washington, DC.

Bakshi VP, Alsene KM, Roseboom PH, Connors EE (2011) Enduring sensorimotor gating abnormalities following predator exposure or corticotropinreleasing factor in rats: a model for PTSD-like information-processing deficits? Neuropharmacology 62:737-748.

Bale TL, Vale WW (2004) CRF and CRF receptors: role in stress responsivity and other behaviors. Annu Rev Pharmacol Toxicol 44:525-557.

Bale TL, Contarino A, Smith GW, Chan R, Gold LH, Sawchenko PE, Koob GF, Vale WW, Lee KF (2000) Mice deficient for corticotropin-releasing hormone receptor-2 display anxiety-like behaviour and are hypersensitive to stress. Nat Genet 24:410-414.

Binder EB, Bradley RG, Liu W, Epstein MP, Deveau TC, Mercer KB, Tang Y, Gillespie CF, Heim CM, Nemeroff CB, Schwartz AC, Cubells JF, Ressler KJ (2008) Association of FKBP5 polymorphisms and childhood abuse with risk of posttraumatic stress disorder symptoms in adults. JAMA 299:1291-1305.

Blanchard DC, Blanchard RJ, Tom P, Rodgers RJ (1990) Diazepam changes risk assessment in an anxiety/defense test battery. Psychopharmacology 101:511-518.

Blanchard RJ, Blanchard DC (1989) Antipredator defensive behaviors in a visible burrow system. J Comp Psychol 103:70-82.

Bremner JD, Licinio J, Darnell A, Krystal JH, Owens MJ, Southwick SM,
Nemeroff CB, Charney DS (1997) Elevated CSF corticotropin-releasing factor concentrations in posttraumatic stress disorder. Am J Psychiatry 154:624-629.

Campbell ML, Morrison AP (2007) The psychological consequences of combat exposure: the importance of appraisals and posttraumatic stress disorder symptomatology in the occurrence of delusional-like ideas. Br J Clin Psychol 46 [Pt 2]:187-201.

Chalmers DT, Lovenberg TW, De Souza EB (1995) Localization of novel corticotropin-releasing factor receptor (CRF2) mRNA expression tospecific subcortical nuclei in rat brain: comparison with CRF1 receptor mRNA expression. J Neurosci 15:6340-6350.

Choi DC, Evanson NK, Furay AR, Ulrich-Lai YM, Ostrander MM, Herman JP (2008a) The anteroventral bed nucleus of the stria terminalis differentially regulates hypothalamic-pituitary-adrenocortical axis responses to acute and chronic stress. Endocrinology 149:818-826.

Choi DC, Furay AR, Evanson NK, Ulrich-Lai YM, Nguyen MM, Ostrander MM, Herman JP (2008b) The role of the posterior medial bed nucleus of the stria terminalis in modulating hypothalamic-pituitary-adrenocortical axis responsiveness to acute and chronic stress. Psychoneuroendocrinology 33:659-669.

Coste SC, Kesterson RA, Heldwein KA, Stevens SL, Heard AD, Hollis JH, Murray SE, Hill JK, Pantely GA, Hohimer AR, Hatton DC, Phillips TJ, Finn DA, Low MJ, Rittenberg MB, Stenzel P, Stenzel-Poore MP (2000) Abnormal adaptations to stress and impaired cardiovascular function in mice lacking corticotropin-releasing hormone receptor-2. Nat Genet 24:403-409.

Cullinan WE, Herman JP, Watson SJ (1993) Ventral subicular interaction with the hypothalamic paraventricular nucleus: evidence for a relay in the bed nucleus of the stria terminalis. J Comp Neurol 332:1-20.

Davis M, Walker DL, Miles L, Grillon C (2010) Phasic vs sustained fear in rats and humans: role of the extended amygdala in fear vs anxiety. Neuropsychopharmacology 35:105-135.

de Kloet CS, Vermetten E, Geuze E, Lentjes EG, Heijnen CJ, Stalla GK, Westenberg HG (2008) Elevated plasma corticotrophin-releasing hormone levels in veterans with posttraumatic stress disorder. Prog Brain Res 167:287-291.

Dong HW, Swanson LW (2004) Projections from bed nuclei of the stria terminalis, posterior division: implications for cerebral hemisphere regulation of defensive and reproductive behaviors. J Comp Neurol 471:396-433.

Dong HW, Swanson LW (2006) Projections from bed nuclei of the stria terminalis, dorsomedial nucleus: implications for cerebral hemisphere integration of neuroendocrine, autonomic, and drinking responses. J Comp Neurol 494:75-107.

Dong HW, Petrovich GD, Watts AG, Swanson LW (2001) Basic organization of projections from the oval and fusiform nuclei of the bed nuclei of the stria terminalis in adult rat brain. J Comp Neurol 436:430-455.

Fink G (2011) Stress controversies: post-traumatic stress disorder, hippocampal volume, gastroduodenal ulceration. J Neuroendocrinol 23:107-117.

Forray MI, Gysling K (2004) Role of noradrenergic projections to the bed nucleus of the stria terminalis in the regulation of the hypothalamicpituitary-adrenal axis. Brain Res Brain Res Rev 47:145-160.

Gillespie CF, Phifer J, Bradley B, Ressler KJ (2009) Risk and resilience: genetic and environmental influences on development of the stress response. Depress Anxiety 26:984-992.

Grillon C, Morgan CA, Southwick SM, Davis M, Charney DS (1996) Baseline startle amplitude and prepulse inhibition in Vietnam veterans with posttraumatic stress disorder. Psychiatry Res 64:169-178.

Gu G, Cornea A, Simerly RB (2003) Sexual differentiation of projections from the principal nucleus of the bed nuclei of the stria terminalis. J Comp Neurol 460:542-562.

Heinrichs SC, Menzaghi F, Merlo Pich E, Britton KT, Koob GF (1995) The role of CRF in behavioral aspects of stress. Ann N Y Acad Sci 771:92-104.

Kishimoto T, Radulovic J, Radulovic M, Lin CR, Schrick C, Hooshmand F, Hermanson O, Rosenfeld MG, Spiess J (2000) Deletion of crhr2 reveals an anxiolytic role for corticotropin-releasing hormone receptor-2. Nat Genet 24:415-419.

Koob GF, Heinrichs SC (1999) A role for corticotropin releasing factor and urocortin in behavioral responses to stressors. Brain Res 848:141-152.

Kuperman Y, Issler O, Vaughan J, Bilezikjian L, Vale W, Chen A (2011) Expression and regulation of corticotropin-releasing factor receptor type 
$2 \beta$ in developing and mature mouse skeletal muscle. Mol Endocrinol $25: 157-169$.

Lee Y, Davis M (1997) Role of the hippocampus, the bed nucleus of the stria terminalis, and the amygdala in the excitatory effect of corticotropinreleasing hormone on the acoustic startle reflex. J Neurosci 17:6434-6446.

Liberzon I, Taylor SF, Amdur R, Jung TD, Chamberlain KR, Minoshima S, Koeppe RA, Fig LM (1999) Brain activation in PTSD in response to trauma-related stimuli. Biol Psychiatry 45:817-826.

Mason JW, Giller EL, Kosten TR, Ostroff RB, Podd L (1986) Urinary freecortisol levels in posttraumatic stress disorder patients. J Nerv Ment Dis 174:145-149.

Najt P, Fusar-Poli P, Brambilla P (2011) Co-occurring mental and substance abuse disorders: A review on the potential predictors and clinical outcomes. Psychiatry Res 186:159-164.

Nelson EC, Agrawal A, Pergadia ML, Lynskey MT, Todorov AA, Wang JC, Todd RD, Martin NG, Heath AC, Goate AM, Montgomery GW, Madden PA (2009) Association of childhood trauma exposure and GABRA2 polymorphisms with risk of posttraumatic stress disorder in adults. Mol Psychiatry 14:234-235.

Neufeld-Cohen A, Tsoory MM, Evans AK, Getselter D, Gil S, Lowry CA, Vale WW, Chen A (2010) A triple urocortin knockout mouse model reveals an essential role for urocortins in stress recovery. Proc Natl Acad Sci U S A 107:19020-19025.

Neylan TC, Lenoci M, Maglione ML, Rosenlicht NZ, Metzler TJ, Otte C, Schoenfeld FB, Yehuda R, Marmar CR (2003) Delta sleep response to metyrapone in post-traumatic stress disorder. Neuropsychopharmacology 28:1666-1676.

Panagioti M, Gooding P, Tarrier N (2009) Post-traumatic stress disorder and suicidal behavior: a narrative review. Clin Psychol Rev 29:471-482.

Paxinos G, Franklin KBJ (2003) The mouse brain in stereotaxic. San Diego: Academic.

Ponomarev I, Rau V, Eger EI, Harris RA, Fanselow MS (2010) Amygdala transcriptome and cellular mechanisms underlying stress-enhanced fear learning in a rat model of posttraumatic stress disorder. Neuropsychopharmacology 35:1402-1411.

Rau V, Fanselow MS (2009) Exposure to a stressor produces a long lasting enhancement of fear learning in rats. Stress 12:125-133.

Rau V, DeCola JP, Fanselow MS (2005) Stress-induced enhancement of fear learning: an animal model of posttraumatic stress disorder. Neurosci Biobehav Rev 29:1207-1223.

Revest JM, Di Blasi F, Kitchener P, Rougé-Pont F, Desmedt A, Turiault M, Tronche F, Piazza PV (2005) The MAPK pathway and Egr-1 mediate stressrelated behavioral effects of glucocorticoids. Nat Neurosci 8:664-672.

Risbrough VB, Hauger RL, Roberts AL, Vale WW, Geyer MA (2004) Corticotropin-releasing factor receptors CRF1 and CRF2 exert both additive and opposing influences on defensive startle behavior. J Neurosci 24:6545-6552.
Risbrough VB, Geyer MA, Hauger RL, Coste S, Stenzel-Poore M, Wurst W, Holsboer F (2009) CRF1 and CRF2 receptors are required for potentiated startle to contextual but not discrete cues. Neuropsychopharmacology 34:1494-1503.

Sananbenesi F, Fischer A, Schrick C, Spiess J, Radulovic J (2003) Mitogenactivated protein kinase signaling in the hippocampus and its modulation by corticotropin-releasing factor receptor 2 : a possible link between stress and fear memory. J Neurosci 23:11436-11443.

Sanford LD, Yang L, Wellman LL, Dong E, Tang X (2008) Mouse strain differences in the effects of corticotropin releasing hormone (CRH) on sleep and wakefulness. Brain Res 1190:94-104.

Sztainberg Y, Kuperman Y, Justice N, Chen A (2011) An anxiolytic role for CRF receptor type 1 in the globus pallidus. J Neurosci 48:17416-17424.

Ströhle A, Scheel M, Modell S, Holsboer F (2008) Blunted ACTH response to dexamethasone suppression-CRH stimulation in posttraumatic stress disorder. J Psychiatr Res 42:1185-1188.

Thoeringer CK, Henes K, Eder M, Dahlhoff M, Wurst W, Holsboer F, Deussing JM, Moosmang S, Wotjak CT (2012) Consolidation of remote fear memories involves corticotropin-releasing hormone (CRH) receptor type 1-mediated enhancement of AMPA receptor GluR1 signaling in the dentate gyrus. Neuropsychopharmacology 37:787-796.

Ulrich-Lai YM, Herman JP (2009) Neural regulation of endocrine and autonomic stress responses. Nat Rev Neurosci 10:397-409.

Van Pett K, Viau V, Bittencourt JC, Chan RK, Li HY, Arias C, Prins GS, Perrin M, Vale W, Sawchenko PE (2000) Distribution of mRNAs encoding CRF receptors in brain and pituitary of rat and mouse. J Comp Neurol 428:191-212.

Vaughan J, Donaldson C, Bittencourt J, Perrin MH, Lewis K, Sutton S, Chan R, Turnbull AV, Lovejoy D, Rivier C (1995) Urocortin, a mammalian neuropeptide related to fish urotensin I and to corticotropin-releasing factor. Nature 378:287-292.

Walker DL, Davis M (1997) Double dissociation between the involvement of the bed nucleus of the stria terminalis and the central nucleus of the amygdala in startle increases produced by conditioned versus unconditioned fear. J Neurosci 17:9375-9383.

Woodward SH, Murburg MM, Bliwise DL (2000) PTSD-related hyperarousal assessed during sleep. Physiol Behav 70:197-203.

Yehuda R (2009) Status of glucocorticoid alterations in post-traumatic stress disorder. Ann N Y Acad Sci 1179:56-69.

Yehuda R, Golier JA, Halligan SL, Meaney M, Bierer LM (2004) The ACTH response to dexamethasone in PTSD. Am J Psychiatry 161:1397-1403.

Yehuda R, Cai G, Golier JA, Sarapas C, Galea S, Ising M, Rein T, Schmeidler J, Müller-Myhsok B, Holsboer F, Buxbaum JD (2009) Gene expression patterns associated with posttraumatic stress disorder following exposure to the World Trade Center attacks. Biol Psychiatry 66:708-711. 